\title{
El relato de viajes como narrativa transmedia
}

\section{Transmedia storytelling on travel stories}

\author{
Adolfo Baltar Moreno \\ Profesor del departamento de Comunicación Social \\ (Universidad Tecnológica de Bolivar - Cartagena de Indias, Colombia) \\ María Clara Valencia \\ Profesora del departamento de Comunicación Social \\ (Universidad Tecnológica de Bolivar - Cartagena de Indias, Colombia)
}

Fecha de recepción: 10 de octubre de 2015

Fecha de revisión: 28 de diciembre de 2015

Para citar este artículo: Baltar Moreno, A. y Valencia, M. C. (2016): El relato de viajes como narrativa transmedia, Icono 14, volumen (14), pp. 181-210. doi: 10.7195/ri14.v14i1.926 


\section{Resumen}

El relato de viajes forma parte de una gran tradición dentro de la cultura occidental que ha servido históricamente para describir, comprender e imaginar otras culturas y sociedades, próximas o lejanas, constituyéndose en un verdadero género narrativo. Este tipo de narración ha sido y es el reflejo de la percepción del mundo a partir del imaginario creado por los narradores viajeros. ¿Cómo aprovechan los autores actuales de relatos de viajes las posibilidades que hoy en día ofrece el universo transmediático? El presente artículo explora la potencialidad que tiene este tipo de relatos como objeto de estudio de las narrativas transmedia, a partir del análisis de una muestra de 80 producciones narrativas basadas en experiencias de viaje y presentadas en diversas ediciones del Festival Le Grand Bivouac (Francia). De igual forma, muestra la existencia de una nueva tendencia contemporánea dentro de esta forma narrativa que trasciende su naturaleza literaria.

Palabras clave: Relatos de Viaje - Narrativas Transmedia - Sociología del Viaje Periodismo de viajes

\section{Abstract}

Travel stories form part of a great tradition inside Western Culture which has served historically to describe, to understand and to imagine other cultures and communities, far or near, being constituted into a real narrative genre. This type of story has been and is a reflection of the perception of the world based on the imaginary worlds created by the travelling narrators. How do modern authors of travel stories take advantage of the opportunities offered by transmedia storytelling? The present article explores the potential of these types of stories as a privileged object of study for transmedia storytelling studies, from the analysis of a sample of 80 narrative productions based on experiences of travel and presented in diverse editions of the Festival Le Grand Bivouac (France). It also shows the existence of a new contemporary trend inside this narrative form that transcends its literary nature.

Key Words: Travel Stories - Transmedia Storytelling - Travel Sociology - Travel Journalism 


\section{Introducción}

"L'important, c'est l'imaginaire des voyageurs"

Guy Chaumereuil

El fenómeno del viaje contemporáneo representa uno de los principales signos distintivos de la globalización y un elemento esencial de la cultura popular de la sociedad occidental. En una sociedad altamente movilizada, el viaje supone el desplazamiento de las relaciones sociales desde el contexto local hacia el contexto global. El relato del viaje supone una capacidad para construir, ampliar, desarrollar o completar la comprensión del mundo.

Para las ciencias sociales, las narraciones de viaje como objeto de estudio son poseedoras de una gran riqueza en tanto que productos porque engloban, entre otras, dimensiones literarias, históricas, económicas, antropológicas o sociológicas. Cada narración del viaje remite a una puesta en escena elaborada por su autor desde el contexto social, cultural e histórico del momento. En la actualidad, y fruto tanto de los avances tecnológicos como de la facilidad en el desplazamiento que caracteriza a la cultura occidental contemporánea, tenemos la oportunidad de asistir a nuevas formas de presentar el relato del viaje.

\subsection{La narración del viaje en la historia}

La experiencia del viaje ha sido objeto de narraciones orales y escritas en todas las culturas y épocas. Estas narraciones son creaciones sostenidas en hechos vivenciales reales y construidas a partir de las experiencias individuales del viajero, que toman, desde su propia subjetividad, la forma de un relato (oral, escrito, filmado...). Couture (1999, p.66) sitúa este tipo de narrativa como una práctica literaria de difícil clasificación:

No es un género como la novela, el teatro o la poesía, sino más bien una práctica literaria que se inscribe en muchos dominios de la escritura [...] se trata de una práctica literaria proteiforme, que posee una larga historia, repartida a través del mundo y que trata sobre todas las regiones del planeta [...] no existe una definición del relato de viaje que describa el conjunto de su práctica. 


\section{MONOGRÁFICO}

Alburquerque (2011, p.19), al referirse al relato de viajes como género literario, habla de su carácter fronterizo con otras serie literarias según los diversos periodos históricos de su producción. Como dicho autor, consideramos el relato de viajes como una narración factual y no ficcional, puesto que se construye a partir de esa experiencia que, realmente, ha tenido lugar en un tiempo y un espacio vividos por el viajero, el cual se convierte en autor-narrador de su propio viaje (por esta razón le denominamos el autor-viajero).

La narración del viaje en occidente (vivido como una experiencia cultural más allá del mero desplazamiento) ya aparece en textos canónicos de la cultura antigua, como la Odisea de Homero (s.VIII a.C.), la Historia de Heródoto (444 a.C.) o la Geografia de Estrabón (29 a.C.)

No es una novedad afirmar que el viaje ha presidido los grandes relatos de la humanidad. Partes importantes de la Biblia o la Odisea, sin ir más lejos, se vertebran en torno a un viaje. Pero aún más. El viaje y su relato no han dejado de tener una presencia constante a lo largo de la historia. Viaje y vida son, en cierto sentido, sinónimos, ya que su fuente y raíz se encuentra en el desplazamiento mismo (Alburquerque, 2011, p.16).

En la Edad Media podemos encontrar los grandes relatos de Marco Polo (1298) o de Pero Tafur (1436). Sin embargo el viaje, entendido como una verdadera actividad cultural y educativa, puede localizarse en el movimiento humanista que nace en Europa en el siglo XVI y que se desarrolla durante los siglos posteriores. El viaje hacia la cuna de la cultura greco-latina se convirtió entonces en un elemento formativo de las élites aristocráticas y burguesas europeas.

En ese siglo, el conocimiento del mundo a través de las visiones de los viajeros se abre a los continentes africano (León el Africano, 1550) y americano (Nuñez Cabeza de Vaca, 1542). En 1605, Cervantes publicará su obra cumbre, basada en los viajes por la península ibérica del Quijote y Sancho Panza.

A partir del siglo XVIII, las narraciones de los viajeros comienzan a describir el nuevo mundo y a releer el antiguo a través de la obra de autores como Goethe o el 
Capitán Cook. Este siglo es también el de la aparición del turismo moderno, reservado en principio a esas élites europeas.

En el siglo XIX asistimos a un aumento de los relatos de viaje a través de la obra de grandes exploradores como Humboldt o Volney, o de grandes escritores que proponen viajes vividos o imaginados, como Robert L. Stevenson, Stendhal, Mark Twain, Henry D. Thoureau, Washington Irving, Joseph Conrad o Julio Verne. La lectura de estas narraciones comienza a popularizarse en una sociedad occidental que tiene un cada vez mayor acceso a la cultura gracias al aumento de los libros editados y a la aparición de la prensa y de las revistas.

Es interesante señalar cómo los avances tecnológicos (la aparición de los medios de comunicación de masas o las innovaciones de los medios de transporte) influyen decisivamente en la proliferación de las narrativas de viaje, imaginadas o reales, así como sobre el acceso del público a su lectura. Si la invención de la imprenta supuso la aparición de la industria editorial y, posteriormente, de la prensa, la navegación a vapor y el ferrocarril producirán grandes flujos migratorios y nuevas posibilidades de viaje. A partir de la segunda mitad de siglo, la fotografía se incorpora a las narraciones de viaje, y en las postrimerías de siglo aparece el cine.

En el siglo XX, especialmente a partir de la Segunda Guerra mundial, el turismo se expande entre las clases medias y se desarrollan nuevos medios de transporte como el automóvil y la aviación comercial. Y las experiencias y relatos de viaje impregnan cada vez más dominios culturales como la literatura (Jack Kerouac, Lawrence Durrell, Bruce Chatwin), el periodismo (Ernest Hemingway, Ryszard Kapucinsky, Dominique Lapierre), la antropología (Lévi-Strauss, Margaret Mead), la fotografia (Charles Clifford, Robert Frank, Ansel Adams) o el cine (los films d'actualité de los hermanos Lumière, Robert Flaherty, Jean Rouch).

\subsection{Narrativas transmedia y relatos de viajeros}

Desde el fin de siglo asistimos a una transformación de las comunicaciones humanas gracias al desarrollo de las telecomunicaciones, al de los medios de transporte y la revolución digital. Y los nuevos medios de comunicación y de información, así 


\section{MONOGRÁFICO}

como sus posibilidades de expansión, están haciendo que las narrativas se transformen. Son estos factores de carácter tecnológico, económico y sociocultural, los que para Jenkins (2008, p.14) iniciaban los procesos de convergencias mediáticas, en donde "cobran especial importancia realidades como la hibridez de géneros y formatos, el multimedia-entendido como la distribución de contenido por diversas plataformas o el relato interactivo" (Costa y Piñeiro, 2012, pp.107-108).

Es en este contexto que aparece el concepto de narrativas transmedia (transmedia storytelling), término empleado por Henry Jenkins en 2003 y que, englobando otros (cross-media, plataformas múltiples, medios híbridos, mercancía intertextual, mundos transmediales, interacciones transmediales, multimodalidad o intermedios), "trata de nombrar una misma experiencia: una práctica de producción de sentido e interpretativa basada en historias que se expresan a través de una combinación de lenguajes, medios y plataformas" (Scolari, 2013, p.25).

Una característica clave de este modelo de narrativa es que los consumidores de los productos adquieren un papel esencial, generando contenidos y participando en el proceso de creación y expansión de los relatos, "situándose en un punto intermedio entre el productor y el consumidor" (Fernández, 2014, citado por García y Heredero, 2015, p. 265). De esta forma, el término prosumidor hace parte intrínseca de las narrativas transmedia.

¿Qué es una narrativa transmedia? Dos son sus rasgos pertinentes. Por una parte, se trata de un relato que se cuenta a través de múltiples medios y plataformas [...] Pero las narrativas transmedia también se caracterizan por otro componente: una parte de los receptores no se limita a consumir el producto cultural, sino que se embarca en la tarea de ampliar el mundo narrativo con nuevas piezas textuales (Scolari, 2014, p. 72).

Si los medios tradicionales construían relatos unidireccionales, el mundo de Internet y la tecnología digital han producido una multiplicación de relatos y lecturas del mundo que, además, pueden ser discutidas, complementadas y ampliadas por sus audiencias. En la actualidad esas audiencias pueden no solo elegir las narraciones que consumen, sino, además, producirlas. 
¿Cómo se han adaptado las narraciones de viaje a esta transformación?

Interrogarnos sobre el imaginario del viaje hoy en día supone también cuestionar la situación inédita en la que se encuentra el viajero contemporáneo. De una parte, ya no hay ningún lugar a conquistar ni ninguna parte en donde poder perderse, ya que todos los continentes, todas las cumbres, todos los desiertos son conocidos en la actualidad. De otra parte, es posible descubrir todo, ya que el planeta entero es por fin accesible: el avión recorta las distancias; las nuevas tecnologías ofrecen un acceso inmediato a los mensajes, a las imágenes, a los rostros del mundo (Lhérété, 2012, párr. 3),

La tradición del relato de viaje no ha sido ajena a las profundas transformaciones experimentadas por la sociedad occidental en el último cuarto de siglo. Estas transformaciones son evidentes en cuanto a: a) la naturaleza del viajero/autor, b) los nuevos discursos narrativos, c) el tipo de soportes y plataformas empleados para su difusión, y d) la experiencia de recepción de los relatos. Pasamos a desarrollar brevemente estos aspectos.

El relato del viaje implica básicamente un autor-viajero, un discurso narrativo elaborado por éste (convertido en un narrador homodiegético), y un potencial receptor del relato. También implica un soporte a través del cual hacer efectiva la llegada del relato al receptor.

Hoy, las características de los autores-viajeros se han diversificado y ampliado. Los viajeros del mundo desarrollado ya no pertenecen a una élite económica ni cultural, ni a un género concreto. Disponen de un acceso relativamente asequible a los medios de transporte. "En la actualidad, el turismo no es un lujo ni la práctica de una minoría: es un fenómeno de la sociedad de consumo y de la cultura de masas de indudable envergadura [...]" (Medina y Arango, 2014, p.46)

Por otro lado, la irrupción del mundo digital ha aumentado extraordinariamente las posibilidades comunicacionales de los seres humanos y multiplicado la capacidad de acceso a la producción de discursos narrativos de todo tipo. Esto ha 


\section{MONOGRÁFICO}

dado como resultado un aumento en la producción de una diversidad de narraciones de viajes difundidas en múltiples soportes y plataformas. Las visiones, los lenguajes narrativos, o las propias temáticas son algunos de los elementos que también han experimentado una transformación, dada la propia heterogeneidad de sus autores.

Si centramos nuestra mirada en los soportes de difusión observaremos que, si el relato de viajes tuvo efectivamente un origen y una tradición principalmente oral y escrita, en su forma contemporánea se ha dotado de nuevas posibilidades de expresión que van más allá de estos dominios. Esas nuevas posibilidades de expresión se alimentan con la aparición de nuevos soportes.

De igual forma se han transformado las condiciones de recepción. El público de una narración de viaje contemporánea lo es a través de la gran pantalla 0 de la pequeña pantalla, pero también mediante exposiciones, conferencias, blogs, redes sociales o canales de video on-line, entre otras posibilidades de recepción.

¿Qué potencialidad tiene el relato de viajes para aprovechar las posibilidades de las narrativas transmedia? ¿Cuáles son los materiales y los medios que permiten expandir el relato narrativo del viaje? ¿Cuál es el papel que juegan los consumidores de estos relatos en su desarrollo o expansión? ¿Existen relatos de viajes transmediáticos? ¿Qué estrategias utilizan los autores-viajeros para transmediatizar sus relatos?

\subsection{Justificación y objetivos de la investigación}

Este trabajo tiene su origen en un estudio sociológico (Baltar, 2013) realizado por encargo del Festival Le Grand Bivouac ${ }^{1}$, un festival cultural creado en 2002 en la localidad de Albertville (Francia) y que tiene por objetivo comprender mejor el mundo a través del testimonio de los grandes viajeros (Association pour Le Grand Bivouac, 2015). 
Le Grand Bivouac, que cada año atrae a más de 20.000 espectadores, hace parte de un conjunto de festivales sobre el fenómeno del viaje y su narración (al menos 15) nacidos en Francia en las últimas décadas del siglo XX y repartidos por la geografía gala (Quiquet, 2014). Festivales que basan su programación en testimonios de viajeros que han hecho de su experiencia de viaje una suerte de relato (audiovisual, escrito, oral, fotográfico, etc.).

Estos festivales responden a la proliferación de una forma de viaje que pretende diferenciarse del turismo de masas y de los destinos y actividades típicamente turísticos, buscando un intercambio humano, de descubrimiento del otro y de su cultura, con un matiz marcadamente humanista. Un viaje que se pretende, intencionadamente, no-turístico, aunque algunos autores como MacCannell (1992) prefieran hablar del etno-turista.

El éxito de estos festivales refleja la atracción que el imaginario del viajero produce en una gran variedad de públicos. Los relatos de viajes que allí se muestran se materializan y vehiculan a través de diversos soportes: libros, films, diarios de viaje, exposiciones fotográficas...dando por resultado productos narrativos (narraciones literarias, narraciones fotográficas, narraciones audiovisuales) que nos permiten acceder a la interpretación del mundo del autor.

La investigación se ha interrogado sobre las posibilidades transmediáticas de los relatos de viaje. Partimos de la premisa de que el relato de viajes contemporáneo, en tanto que forma narrativa, posee las características necesarias para convertirse en objeto de estudio de las narrativas transmedia. De esta forma, el trabajo ha tenido como objetivo principal el de explorar el relato de viajes contemporáneo describiendo los elementos que posibilitan su transmediatización.

\section{Material y métodos}

Nuestro objeto de estudio es el relato de viajes contemporáneo. Entendemos por relato de viajes la transposición de una determinada experiencia de viaje en una narración construida por el propio viajero, y compartida a través de un determinado soporte o medio narrativo. La experiencia del viaje se constituye así en un universo narrativo. 


\section{MONOGRÁFICO}

El universo de la investigación lo han constituido un conjunto de productos narrativos de viaje elaborados a partir de 2006. Para conformar la muestra se empleó un muestreo estratégico no probabilístico, dada la finalidad exploratoria del estudio. Concretamente, se trató de un muestreo por conveniencia, en el que se incluyeron los productos narrativos programados para la edición más reciente del Festival Le Grand Bivouac (2015) y los de las ediciones 2010 y 2012, éstos últimos debido a la accesibilidad a su programación para los investigadores. La muestra final la compuso un corpus de 80 productos realizados por 116 autores y presentados -mediante diversas plataformas mediáticas- en dichas ediciones del festival.

La técnica principal de recogida y análisis de la información ha sido el análisis de contenido. Como instrumento de recolección de datos se elaboró una ficha de observación creada por los investigadores para identificar los productos narrativos y explorar sus posibilidades de transmediatización. Esta guía registró las características de los autores-viajeros (autoría, género, edad, profesión, medio de desplazamiento), las características del producto narrativo principal (título, sinopsis, temática del viaje, fuente de financiación), y los soportes y plataformas empleados para promocionar y expandir los relatos de la muestra.

El análisis se realizó entre los meses de julio y agosto de 2015. El procedimiento realizado consistió en la exploración de los contenidos de los productos a través del sitio web del festival, y su posterior rastreo mediático en la red (esto es, el desarrollo y extensión del producto narrativo -el relato del viaje- a través de diversos soportes y medios). Este análisis ha hecho hincapié en el uso que los autores-viajeros han concedido al empleo de diferentes medios, soportes y plataformas para desarrollar y extender esos productos narrativos, basándose en los postulados de los principios fundamentales de la narrativas transmedia propuestos por Henri Jenkins (2008) : Expansión Vs. Profundidad, Continuidad vs. Multiplicidad, Inmersión vs. Extrabilidad, Construcción de mundos, Serialidad, Subjetividad y Realización. 


\section{Resultados}

\subsection{Características de los autores-viajeros}

La mayoría de los 116 autores-viajeros son de nacionalidad francesa (105 autores). El resto de autores son, en su mayoría, de procedencia europea (3 italianos, un alemán, un belga y un suizo) Hay un iraní y dos marroquíes. El continente americano aporta los relatos de una canadiense y de una argentina.

Podemos destacar la gran presencia de mujeres en la autoría de los relatos, si bien todavía inferior (45\%) a la del hombre. Si históricamente hemos visto cómo el protagonismo del relato de viajes ha tenido nombre masculino, en la actualidad la mujer participa en igualdad de condiciones que el hombre tanto en el viaje como en la elaboración de su relato.

La edad no es en la muestra un elemento determinante a la hora de construir un producto narrativo del viaje: el $93 \%$ de los autores-viajeros se mueve en la franja entre los 18 y los 50 años.

En cuanto a la procedencia profesional de los autores, observamos que un 33\% se declaran realizadores audiovisuales, lo que implica que tienen una formación audiovisual (sin especificar si es de carácter técnico o universitario). Si añadiésemos aquí a los periodistas (13\%), a quienes se les supone una cierta formación en este campo, la suma total de autores viajeros que tienen formación audiovisual llegaría al $46 \%$ de los productos analizados.

El 54\% restante tiene ocupaciones que no están relacionadas claramente con el audiovisual. Este dato es interesante, dado que el $64 \%$ de los productos narrativos principales de la muestra son documentales audiovisuales. Esto supone que un número importante de los viajeros ha realizado sus narrativas audiovisuales sin que la producción y realización audiovisual haga aparentemente parte de su formación u ocupación principal, lo que sugiere un elemento de amateurismo en las producciones audiovisuales. De hecho, el amateurismo en las propuestas de 


\section{MONOGRÁFICO}

los autores viajeros más jóvenes no está considerado un motivo de exclusión para poder participar en el festival.

\subsection{Características de los productos narrativos de viaje}

La muestra analizada ha comprendido 80 narrativas de viaje realizadas entre los años 2006 y 2015 y presentadas en las diferentes ediciones del festival, observándose un aumento paulatino de la producción a partir del periodo 2008/2009, que se mantiene después constante.

\begin{tabular}{|c|c|}
\hline AÑO DE PRODUCCIÓN & NÚMERO DE PRODUCTOS \\
\hline 2006 & 1 \\
\hline 2007 & 5 \\
\hline 2008 & 13 \\
\hline 2009 & 6 \\
\hline 2010 & 14 \\
\hline 2011 & 13 \\
\hline 2012 & 4 \\
\hline 2013 & 8 \\
\hline 2014 & 14 \\
\hline 2015 & \\
\hline & \\
\hline
\end{tabular}

Tabla 1: Año de producción de las narrativas de la muestra 


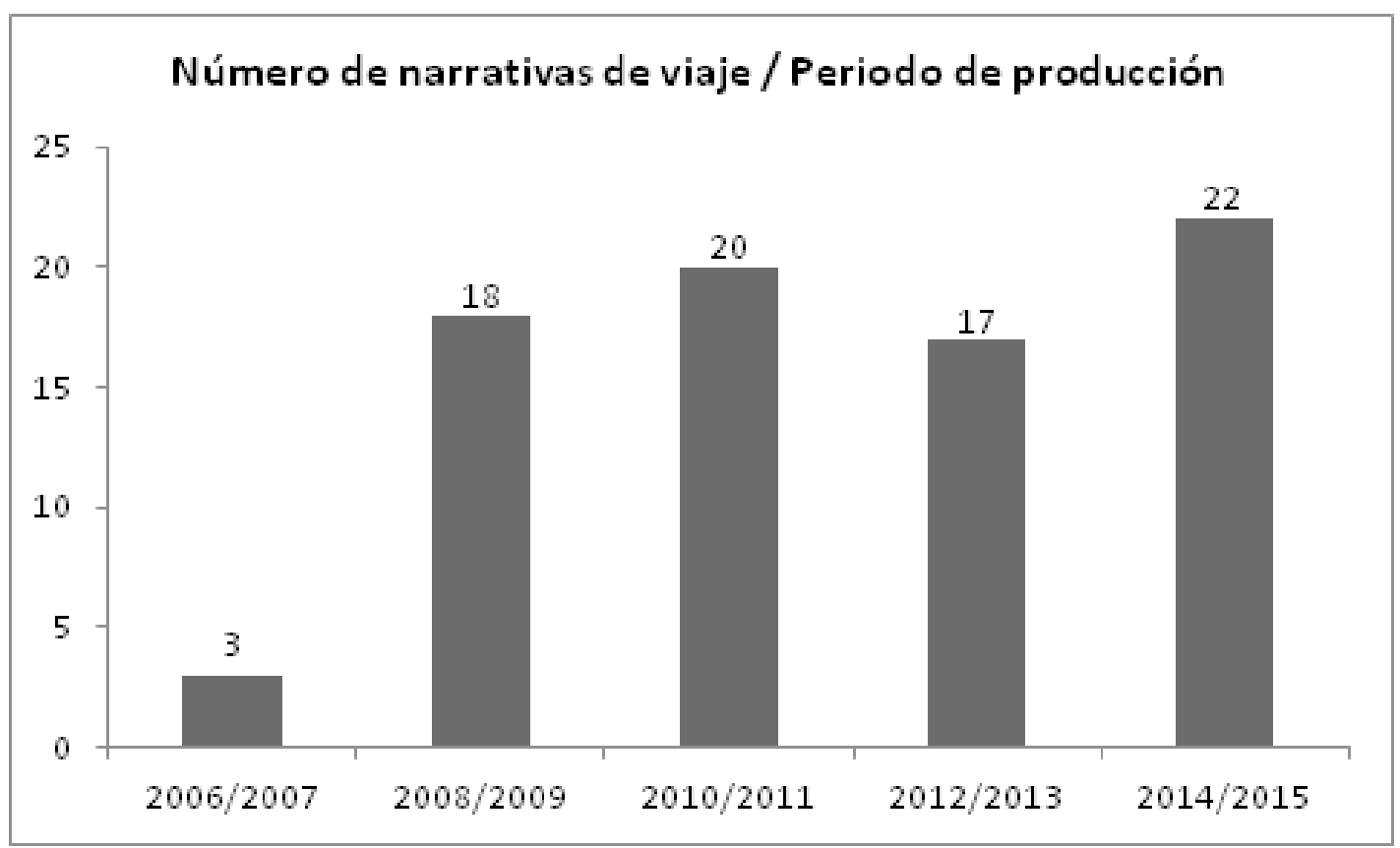

Figura 1: Número de narrativas/ Periodo de producción. Fuente: Elaboración propia

Si de las narrativas de viaje analizadas, una mayoría (61\%) están realizadas por un único autor, el número de productos firmados por dos o más autores es significativo (31 productos representando un 39\% del total). Dentro de los productos mixtos, hay una mayoría de productos firmados por equipos mujer-hombre $(67 \%)$. Los equipos compuestos únicamente por mujeres representan un $20 \%$ de esa categoría, y los compuestos únicamente por hombres un $13 \%$.

Con respecto a la financiación, los datos nos indican que una mayoría de los relatos de viaje se han financiado con recursos propios de los autores-viajeros (52\%) o haciendo uso del recurso al crowdfunding o a la petición de donaciones a particulares $(10 \%)$. Solamente un $20 \%$ especifican claramente haber recibido financiación pública o privada, entendiendo por esta última aquella recibida por empresas patrocinadoras o partenaires. 


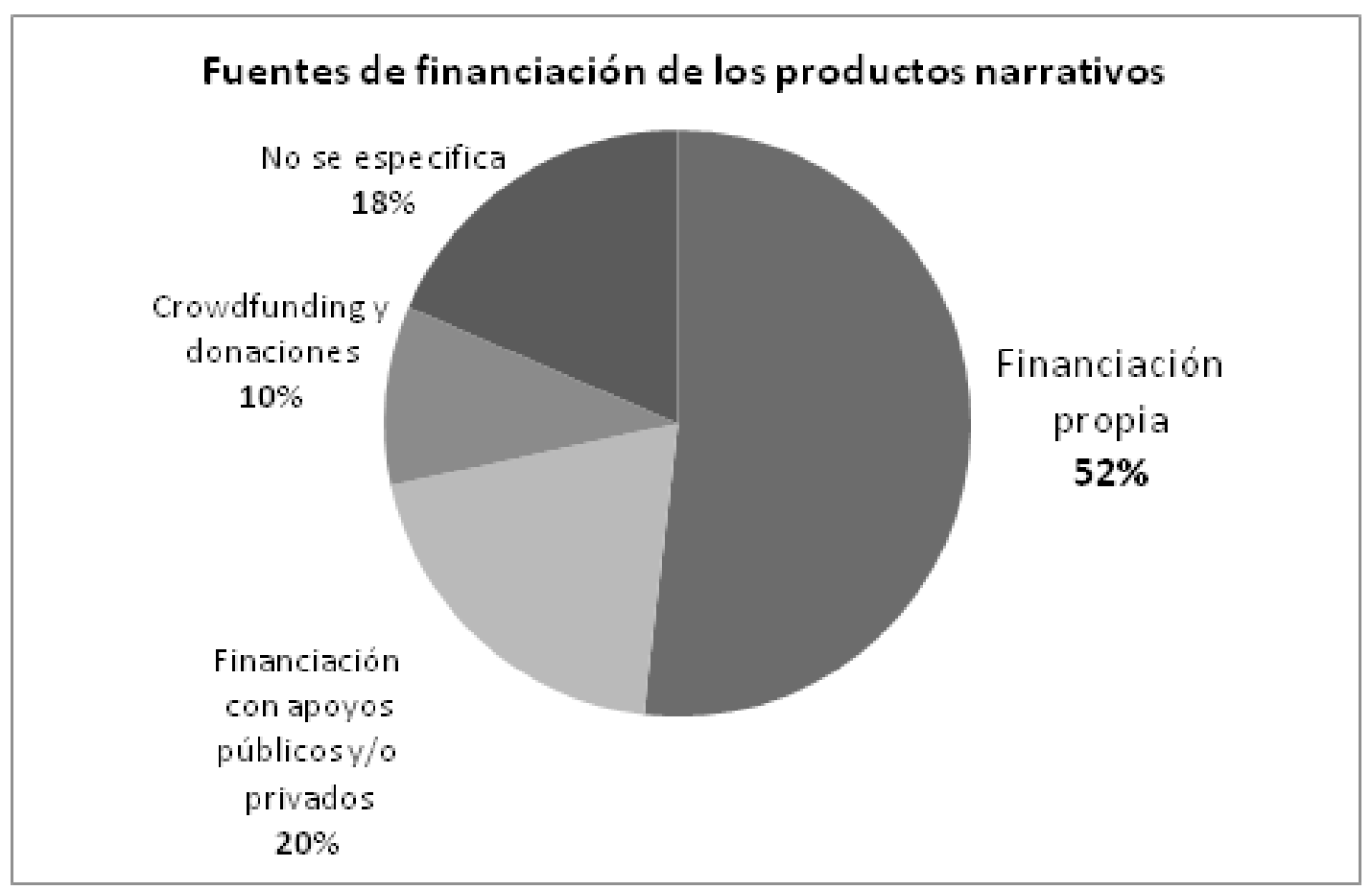

Figura 2: Fuentes de financiación de los productos narrativos. Fuente: Elaboración propia

Con respecto a las geografías visitadas y narradas, el continente asiático es el más visitado (un 39\% de los relatos analizados transcurre allí).

Europa es el segundo destino de estos viajeros, bien como punto de destino del viaje, bien como punto de tránsito, principalmente Europa del Este y Rusia (21\% de los relatos). Al viejo continente le sigue América Latina, en particular las culturas andinas e indígenas (17\%). África ocupa el cuarto lugar (12\% de los relatos) y Norteamérica el quinto ( $7 \%$ ). Oceanía es el continente con menos relatos (4 en total). Hay que especificar que 14 relatos (un $18 \%$ del total) transcurren en más de un continente. 


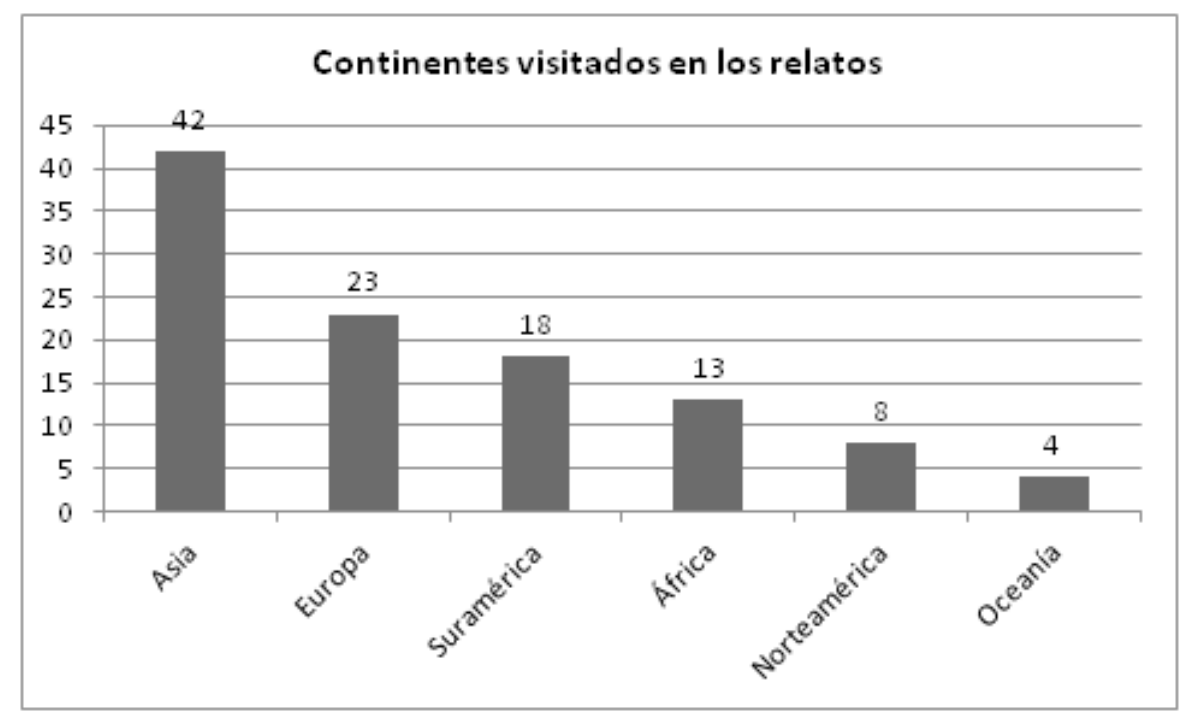

Figura 3: Continentes visitados en los relatos. Fuente: Elaboración propia

En cuanto a las temáticas, hacemos notar que un mismo relato puede contener varias. Las más numerosas son aquellas relacionadas con un viaje con fines antropológicos o etnográficos, presentes en 39 relatos, suponiendo un $28 \%$ del total de la muestra.

Le siguen las temáticas que se basan la categoría que hemos denominado el viaje como experiencia humana, y que reflexionan sobre el propio hecho del viaje como experiencia educativa y cultural para el viajero. Suponen un $12 \%$ del total de la muestra, estando presentes en 17 relatos.

La siguiente categoría temática, con una presencia similar a la anterior (16 relatos, un $10 \%$ del total), es la de los relatos cuya temática se basa en realizar una determinada denuncia social respecto a la situación de diversos grupos humanos visitados. Las temáticas sobre el viaje de aventura están presentes en un $10 \%$ de los relatos.

Otras temáticas presentes en los relatos son los referidos a la ecología y medioambiente (9 relatos, 7\% del total de la muestra), educación (7 relatos, 5\%), asociacionismo (7 relatos, 5\%), y religión/espiritualidad (7 relatos, 5\%). 


\section{MONOGRÁFICO}

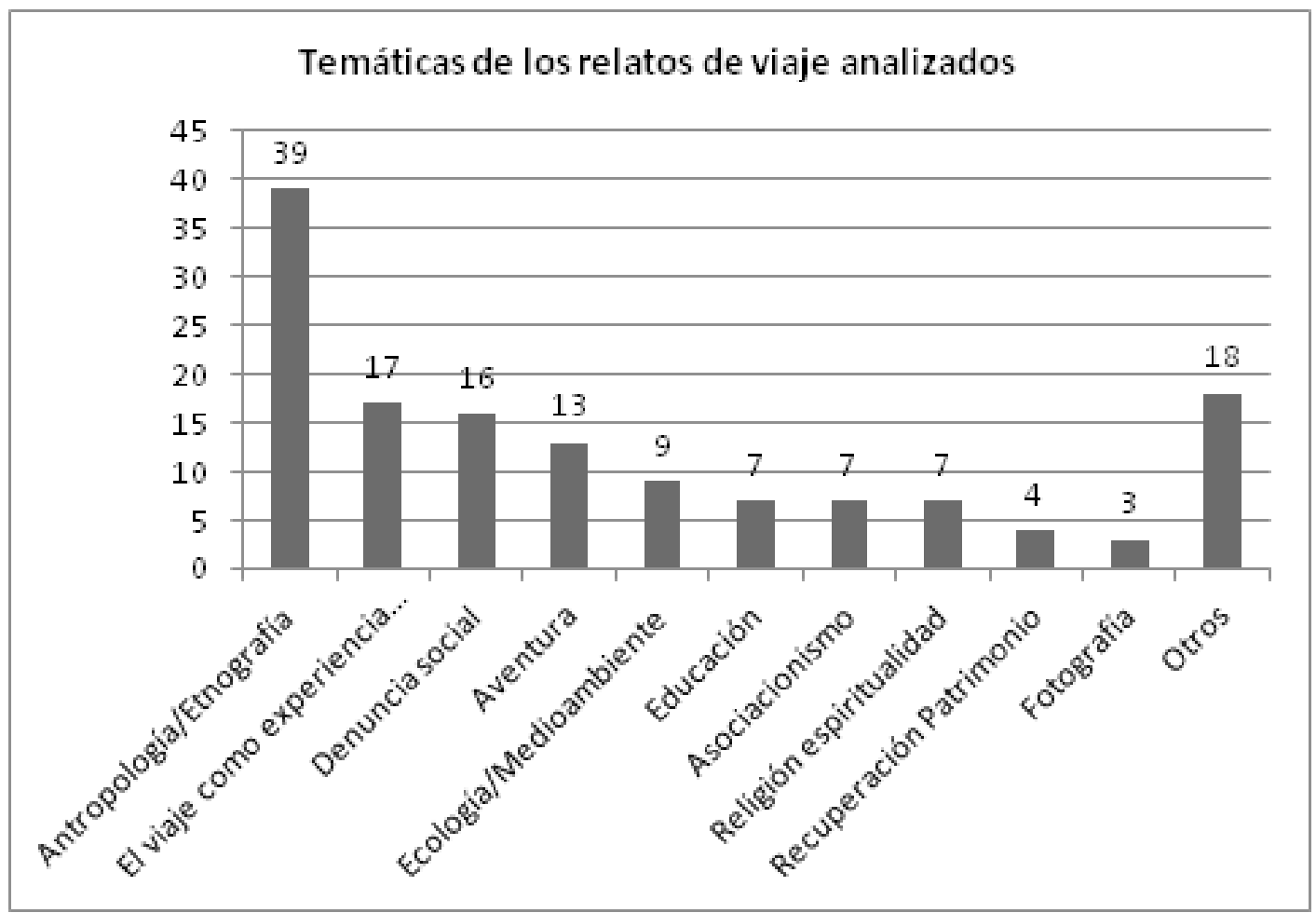

Figura 4: Temáticas de los relatos de viaje analizados. Fuente: Elaboración propia

\subsection{Soportes y plataformas de los productos narrativos}

Cada una de las narraciones de viaje se presenta a priori en un producto narrativo principal. A este respecto, los resultados muestran una elevada producción narrativa de carácter audiovisual en formato de video o cine, con 51 documentales que constituyen el grueso de la programación de estas ediciones, y que suponen un $64 \%$ de la muestra.

También se destacan los diaporamas (21 en el conjunto total), representando un $26 \%$ de la programación en las diversas ediciones del festival. Estos diaporamas, como si de películas se tratara, se proyectan en diversos horarios con o sin la presencia de sus autores. Así, el $90 \%$ de los productos narrativos principales emplean el lenguaje audiovisual. 
El restante $10 \%$ lo constituyen dos libros (uno de ellos un foto-libro), un sitio web, una serie de televisión y una exposición fotográfica.

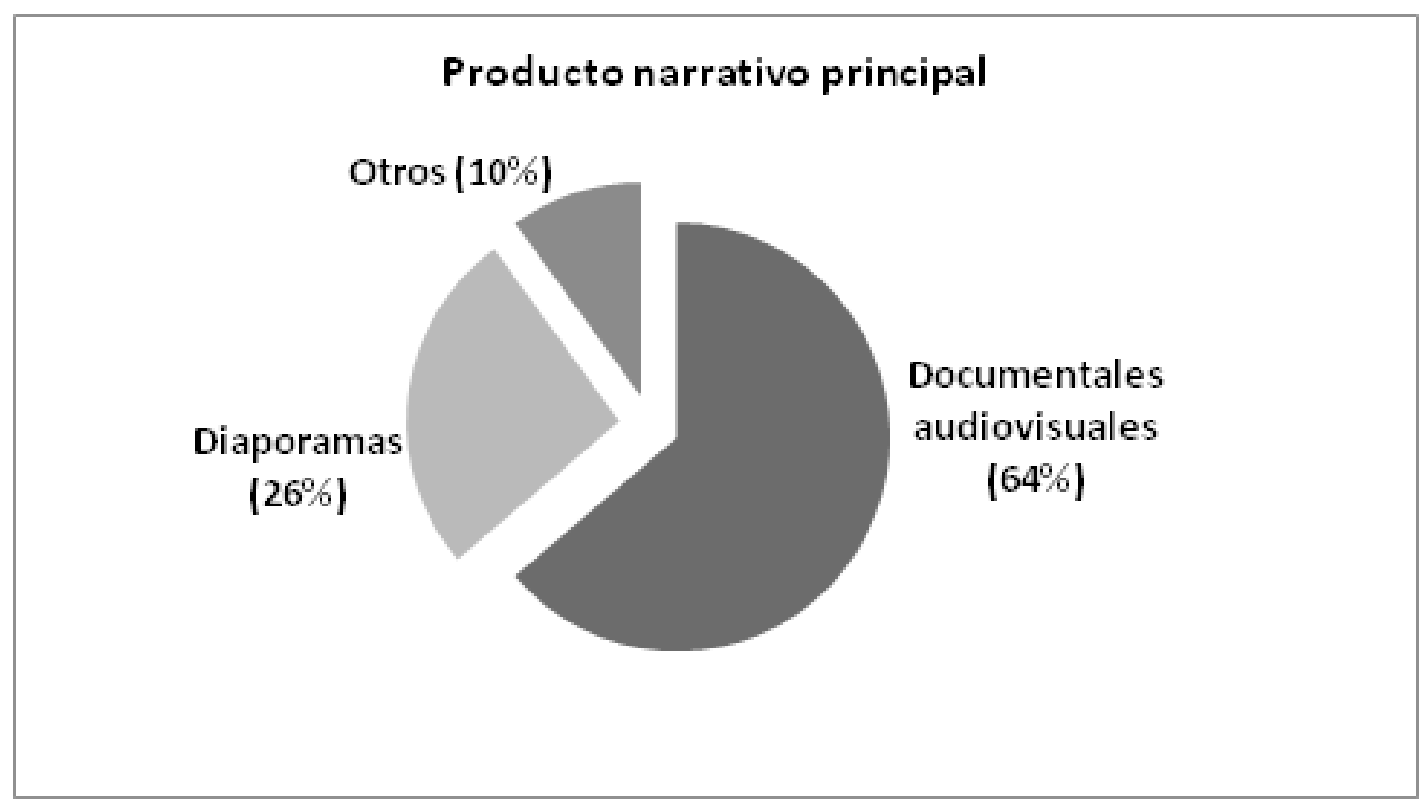

Figura 5: Producto narrativo principal. Fuente: Elaboración propia

Estos productos narrativos principales se acompañan por otros que acompañan, complementan y, en ocasiones, suplen a la narración principal del viaje a través de otro tipo de medios, continuando el relato principal o estableciendo nuevos giros o perspectivas del viaje narrado.

De esta manera, un $71 \%$ de los relatos de viaje (57 relatos) se presentan con tres o más productos narrativos complementarios. Es más, el 55\% (44 relatos) ofrece cuatro o más productos complementarios. Únicamente en 3 casos no existe producto narrativo complementario alguno, lo que representa únicamente el $4 \%$ de la muestra. Cada experiencia de viaje convertida en relato se expande así en diversos medios. 


\section{MONOGRÁFICO}

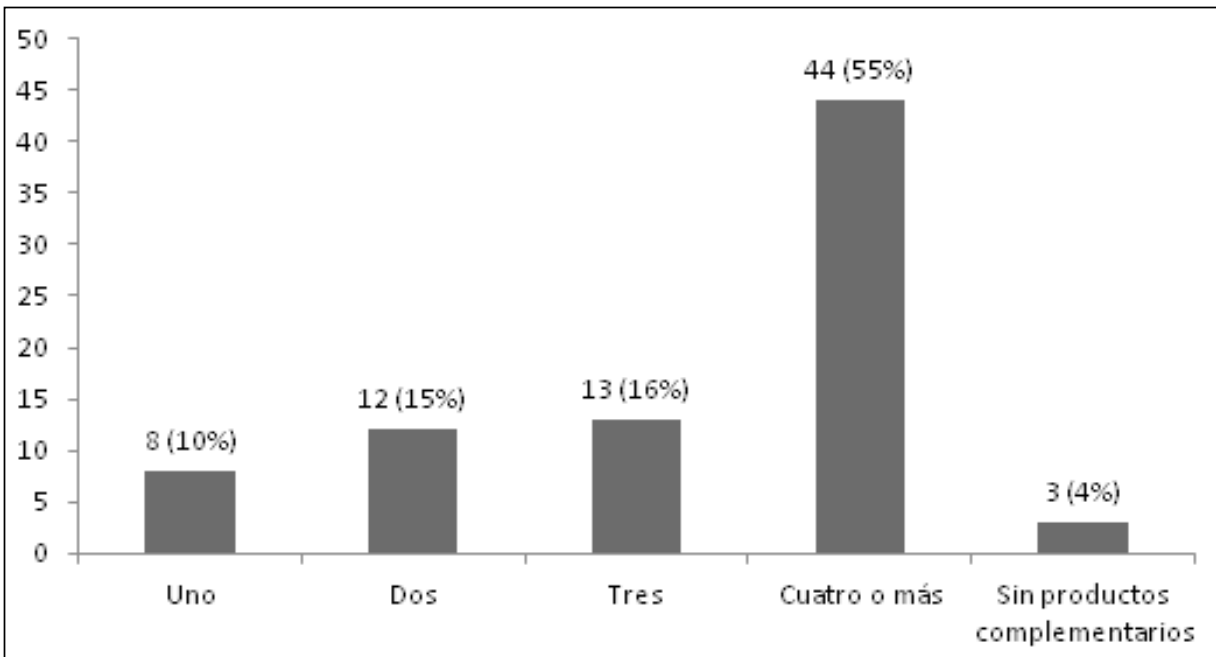

Figura 6: Número de productos narrativos complementarios que acompañan al producto principal Fuente: Elaboración propia

¿En qué medios se continua el relato del viaje? Los relatos analizados se transmediatizan en diversas formas narrativas y soportes, promoviendo la continuidad y ramificación de su contenido e incluso creando relatos diferentes. Hemos identificado un total de 172 productos narrativos complementarios al producto narrativo principal que se distribuyen como muestra el siguiente gráfico:

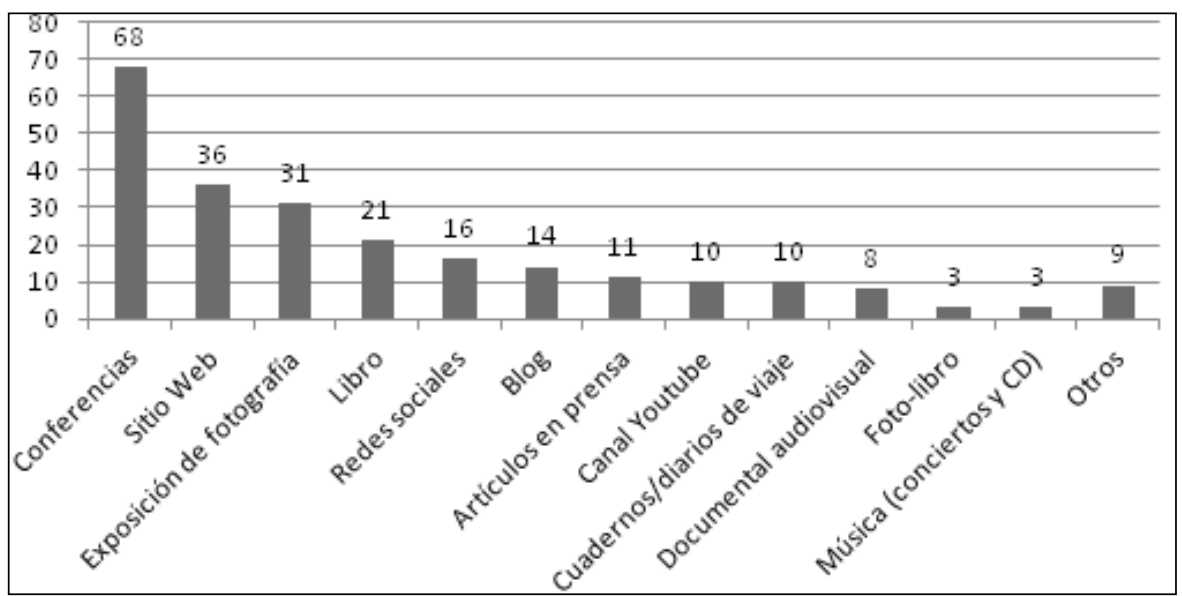

Figura 7: Productos narrativos de la experiencia del viaje en otros medios y soportes. Fuente: Elaboración propia 
Estos medios y soportes se convierten en estrategias alternativas para la distribución del producto narrativo principal. En algunos casos suponen también la creación de nuevos relatos distintos al principal, fruto de la misma experiencia de viaje. Un ejemplo es el proyecto Pianotrip (Nils y Clavet, 2015) en el que sus autores, tras una travesía en bicicleta de 7.000 kilómetros recorridos por Europa entre 2010 y 2011, produjeron un documental audiovisual, una exposición fotográfica, un libro, y un espectáculo a medio camino entre el cine-concierto y el teatro; los autores ofrecen además una conferencia, y disponen de un sitio web de promoción del proyecto. Ejemplos similares son Un an sur la route du lait (Dahan y Mingasson, 2006) o Asiemut (Higgins y Carrier, 2015).

Las conferencias son el principal medio de continuidad del relato, estando presentes en 68 de los 80 relatos analizados. En ellas, los autores-viajeros acompañan oralmente la presentación del producto principal (sea un documental, un diaporama u otro), construyendo un nuevo relato sobre la experiencia de viaje que comparten con un público presencial. Tras su discurso oral, se someten además a la preguntas del público. En varios casos -a los proyectos ya mencionados podemos añadir Paysan Vagabond (Cottereau, 2013) o Diary--Baïkal-Bangkok (Riegel, 2012) - estas conferencias no se preparan exclusivamente para el festival, sino que hacen parte de la expansión del producto narrativo y son ofrecidas a instituciones educativas y culturales o asociaciones, así como a otros festivales.

El libro, uno de los soportes tradicionales del relato de viajes, es empleado para narrar 21 experiencias. Además, hemos identificado 4 foto-libros. El relato escrito también está presente en forma de cuadernos de viaje (10).

Las exposiciones de fotografía, presentes en 31 experiencias de viaje, son otro importante medio de difusión, constituyendo en sí mismas un relato visual propio dirigido hacia un público presencial, que se ofrece no solamente para este festival en concreto, sino para otras instituciones. En el sitio web Litosphère (Guérin, 2015) se ofrecen hasta nueve exposiciones sobre diferentes temáticas del mismo autorviajero, y en los productos 8 ans à vélo, Japon o Mekong (Lepre y Lepre, s.f.), los autores promocionan el alquiler de un espectáculo basado en un diaporama digital acompañado de una conferencia. 
Los sitios web, presentes en 36 experiencias de viaje, forman parte de la estrategia de distribución de los productos principales, con una estructura narrativa que habla tanto del propio producto principal como de los autores -su biografía, sus objetivos...-, y de los patrocinadores (tanto del viaje como de la realización del producto). Varios autores se sirven de estos sitios web para presentar otros relatos de viajes producidos por ellos en el pasado e incluso creando una suerte de personaje narrativo en torno a sí mismos (Riegel, 2015). En algunos casos se ofrecen a los internautas (un público digital) consejos para preparar diversos aspectos del viaje (la forma de entablar el contacto con las comunidades, el equipaje necesario o los medios de desplazarse por las regiones visitadas en el relato), como sucede en Notre voyage à vélo en Eurasie (Étienne y Marion, 2015).

Las redes sociales (Facebook, Twitter, Instagram...) se emplean en 16 relatos y se utilizan tanto para promocionar el producto narrativo principal -es el caso de Le Degré 6 du voyageur (Gans, 2015) o Sur la route du soleil levant (Bailly, 2010-, como para compartir la experiencia del viaje; así sucede en Indochine, sur la Piste rouge (Clocheret y Picard, 2015). Los canales de video en red como YouTube o Vimeo son empleados por 10 autores. Por su parte, los blogs lo hacen en 14, como On plie bagage (Houlbert y Temps, 2014) o Cin'énergie (Palenzuela y Mercat, 2015).

Encontramos 8 documentales audiovisuales empleados como productos complementarios al principal. Hemos incluido también productos musicales que, en forma de $C D$, aparecen asociados al relato central como fruto de la experiencia del viaje, y que están presentes en 3 experiencias de viaje.

Otros tipos de productos narrativos complementarios utilizados por los autoresviajeros han sido los siguientes: exposiciones de dibujos del viaje, making off de los documentales, diaporamas, newsletters y reportajes de televisión.

\section{Discusión}

¿Podemos hablar de relatos de viaje transmedia? García y Heredero (2015) proponen un modelo de análisis de la estructura de las narrativas transmedia enten- 
diéndolas como una gran macrohistoria de la que, a partir de una línea cronológica, se crean nuevos contenidos oficiales y otros generados por el usuario/público. En el caso que nos ocupa, se macrohistoria se ocupa de la experiencia de viaje, presentada inicialmente en un relato principal presentado en un soporte/medio determinado para luego expandirse en otras narraciones complementarias o paralelas que emplean otros medios para su difusión.

Por su parte, Jeff Gómez (citado por Scolari, 2010) sostiene que una de las claves que caracterizan una narrativa transmedia es la de distribuir el contenido en al menos 3 diferentes plataformas mediáticas. En nuestra muestra, esto sucede en un $71 \%$ de los productos narrativos. El material narrativo de los autores-viajeros no se limita al soporte principal del relato. Esto ya hace de ellos narraciones crossmedia en el sentido de Costa y Piñeiro (2012, p. 111), para quien cada uno de los soportes aporta información para la construcción de un gran relato unitario (la experiencia del viaje).

Pero encontramos además que el viaje y su narración tienen no solamente su continuidad, sino incluso un hilo narrativo propio a través de otros medios. De una misma experiencia de viaje se desarrolla una narración principal y otras narraciones complementarias e incluso independientes, planteando enfoques y situaciones no contemplados en la trama principal. Para ello se emplean diversos formatos mediáticos, generando piezas únicas de contenido para cada canal.

En esto coinciden con la definición de narrativas transmedia de Belsunces (2001, p.24): "aquellos relatos interrelacionados que están desarrollados en múltiples plataformas, pero que guardan independencia narrativa y sentido completo. De tal forma, cada fragmento de la historia se puede experimentar de forma individual aunque todos ellos forman parte de un relato global".

El uso de estos diversos soportes narrativos para relatar una misma experiencia de viaje mediante diversos relatos da cuenta de las posibilidades de su transmediatización. Varios de los productos narrativos analizados son de facto narrativas transmediáticas: Es el caso del proyecto Pianotrip (Nils y Clavet, 2015), de 


\section{MONOGRÁFICO}

Asiemut (Higgins y Carrier, 2015), del proyecto Marche autour du monde pour la paix et les enfants (Béliveau, 2015), o de Un an sur la route du lait (Dahan y Mingasson, 2006). Sus autores han creado deliberadamente verdaderas estrategias transmedia para que los públicos se relacionen con su experiencia de viaje por medios diferentes.

En el siguiente gráfico mostramos las posibilidades de transmediatización del relato que hemos identificado en nuestra muestra ( $\mathrm{y}$ que no excluyen que puedan emplearse otros medios):

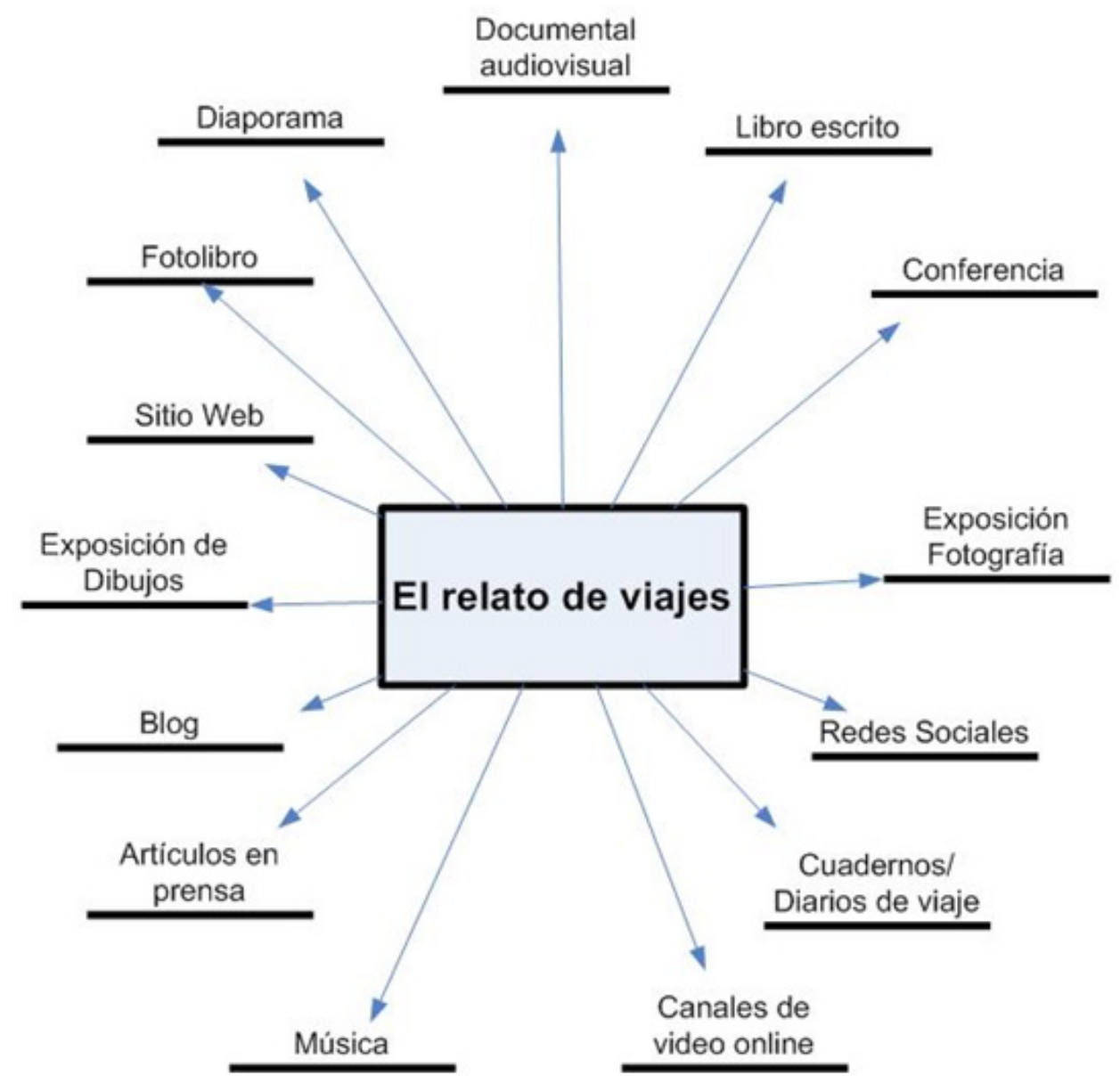

Figura $n^{\circ}$ 8: Posibilidades de transmediatización del relato de viajes. Fuente: Elaboración propia 
Un segundo elemento que sustenta la potencialidad transmedia de los relatos de viaje pasa por la participación de sus públicos en la expansión de los relatos. ¿Cómo es esta participación?

En una gran parte de las producciones analizadas en nuestro corpus la narración de la experiencia de viaje se dirige tanto a lectores y espectadores como a públicos presenciales y digitales. Varios autores-viajeros están presentes además en espacios físicos (a través de la presentación de sus relatos en festivales y en otras instituciones) y virtuales (a través de las redes sociales y los blogs, que de alguna forma suponen una especie de diario de viaje). En estos espacios sus públicos pueden interactuar con ellos no solamente a lo largo del viaje, sino también antes y después del mismo, aportando comentarios, consejos y preguntas a los autores. Esta participación del público constituye un elemento más del universo narrativo.

Hallamos en estos públicos los diferentes tipos de consumidores del producto transmedia que propone Scolari (2009, p.597): consumidores de un único texto (generalmente lo que hemos denominado como el producto narrativo principal), consumidores de un único medio (no necesariamente el del producto narrativo principal) y consumidores transmedia (el usuario consume todas las propuestas narrativas del autor-viajero, la principal y las secundarias).

A este respecto, algunos autores-viajeros han conseguido crear sus públicos y fidelizarlos: sus experiencias de viaje son seguidas por diversos medios y sus apariciones en diversas ediciones del festival, presentando en cada edición del festival nuevos relatos de viajes, son esperadas por los espectadores. Hay una suerte de fenómeno fan en torno a las propuestas narrativas de determinados viajeros $^{2}$.

En cuanto a los espacios digitales, en donde el público puede interactuar y participar de la narrativa de viaje, estos consisten en los propios blogs de los autores, en los comentarios en las redes sociales, en los tweets. Los viajes narrados de manera sincrónica a su realización, al ser experiencias a largo plazo, pueden 
aprovechar mejor la transmedialidad para expandir la historia y llegar a públicos más amplios y diversos.

No menos importante es la presencia física del público en las conferencias, en donde interactúan con los autores-viajeros en torno al relato principal. Los festivales de viaje se convierten en plataformas mediáticas utilizadas por los propios autores, pero también en un espacio donde inspirar al público para llevar a cabo tanto la acción del viaje como su narración. Quizá porque, como afirma Romero Tobar (2005, p.19), los relatos de viaje se nutren tanto de la experiencia real del viajero como de la escritura de relatos anteriores. Algunos de los autores-viajeros de nuestra muestra, antes de serlo, fueron parte del público del festival, como Caroline Riegel o Antoine Cottereau.

Podemos así observar la existencia de un tipo de público del relato de viajes que, según la clasificación de usuarios propuesta por Guerrero (2014, pp.239-267) encajaría en un modelo creativo/divulgativo, aquel capaz de generar un contenido que contribuye a la expansión del universo narrativo original. Es más, si seguimos la tipología de usuarios de productos transmedia ofrecida por García y Heredero (2012, p. 267) el usuario del relato de viajes es aquí tanto observador, como difusor, discursivo, y creador del mismo.

Teniendo en cuenta la información recolectada, podemos afirmar la existencia de un nuevo modelo de narrativa del viaje contemporáneo, caracterizada por, al menos, los siguientes elementos:

- Hay un uso constante de las nuevas tecnologías, tanto para la creación y producción de los relatos como para su difusión.

- El lenguaje audiovisual se ha convertido en una alternativa al escrito como medio narrativo.

- La autoría de los relatos es intergénero, interclase e intergeneracional.

- El componente amateur está permitido en la creación de los relatos, lo que en ocasiones aporta un valor añadido para sus públicos. 
- Son productos narrativos autofinanciados en una gran parte de los casos por los propios autores-viajeros.

- Son narrativas elaboradas desde un enfoque humanista: sus contenidos se basan en valores humanos, promoviendo un viaje de encuentro con el otro, con el diferente, y valorizando la diversidad y riqueza del mundo.

- Hay una intención deliberada en los autores de estos relatos de distanciarse de la idea del turismo organizado, alejándose de los destinos y alojamientos convencionales, empleando medios de transporte alternativos y buscando ese encuentro con el otro que este tipo de turismo no facilita. De esta forma, pretenden simbolizar una suerte de cultura "contraturística".

- Son relatos que transcurren en geografías globales, dada la accesibilidad de los viajeros occidentales para acceder a cualquier parte del planeta.

- La interactividad y la participación con el público pasa a ser un elemento prioritario en estas narrativas. Los autores-vajeros tienen presentes a sus públicos tanto para financiar los viajes y la producción de sus relatos como para su difusión. Estos públicos, a su vez, enriquecen las narrativas con su participación.

- Cada experiencia de viaje narrada es promocionada a través de diversas plataformas y soportes y tiene capacidad de transmediatizarse.

- Estos relatos comparten un elemento transversal: sus autores entienden el viaje como experiencia cultural y formativa para el viajero, y promueven la cultura del viaje y de su narración entre su público.

Si no todos los relatos de viaje analizados son transmedia, los ejemplos ya mencionados de los que sí lo son confirman que todos ellos son susceptibles de transmediatizarse. Es una decisión que, a priori, pertenece a sus autores originales. 


\section{MONOGRÁFICO}

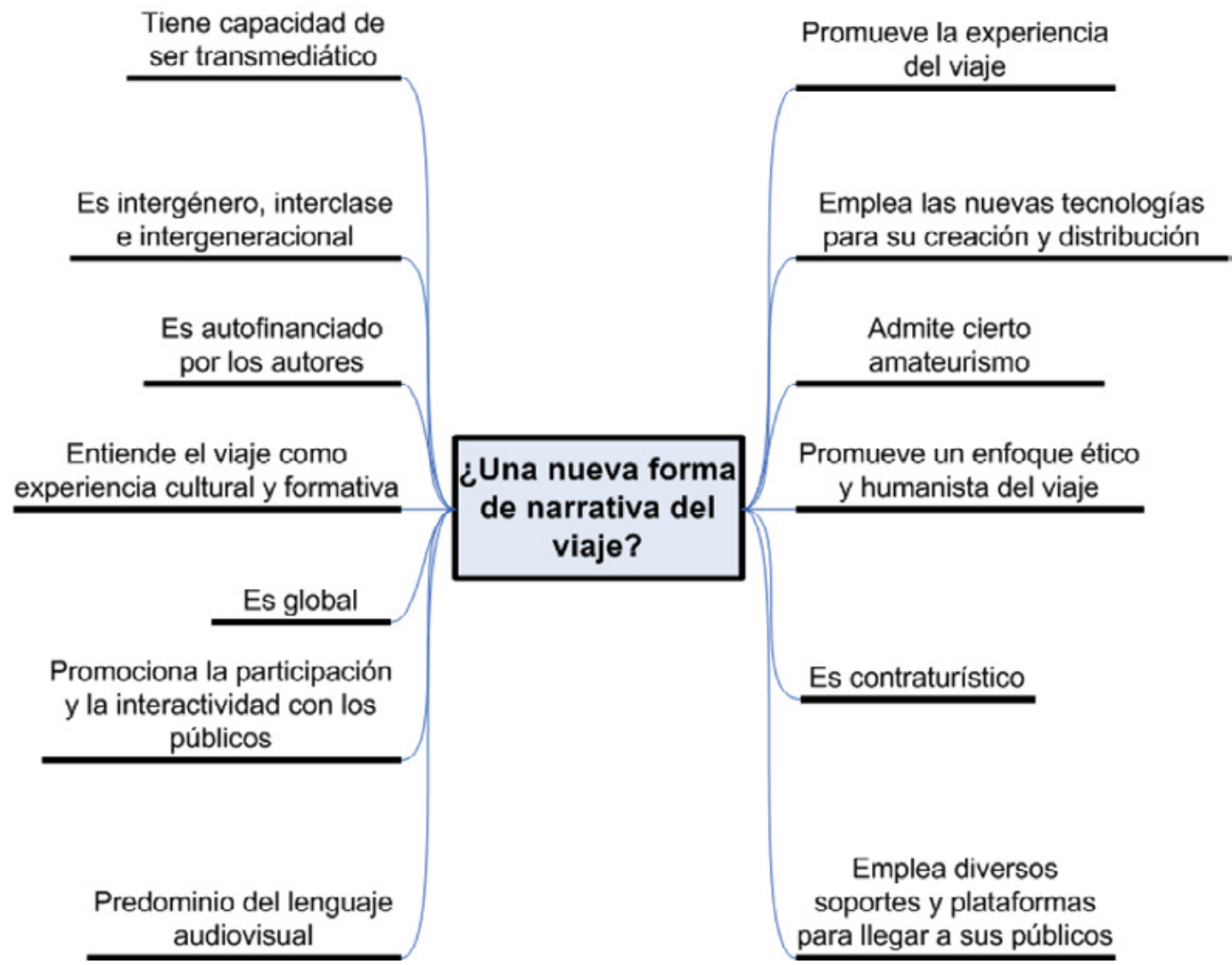

Figura 9: El relato de viajes contemporáneo: ¿una nueva forma narrativa del viaje?

Fuente: Elaboración propia

En nuestra era digital, los autores-viajeros emplean los soportes propios de la misma: el libro tradicional cohabita con el video, la fotografía, o la propia red (blogs, sitios web, redes sociales), que ofrece la oportunidad de promover sus producciones y de llegar a nuevas audiencias, contribuyendo a la multiplicación de sus imaginarios.

Esta discusión nos lleva a concluir con una reflexión sobre el viaje contemporáneo y sobre su relato. En cuanto al primero, ¿nos encontramos ante una nueva forma de entender el viaje? Fenómenos como los vuelos low cost y el aumento del turismo de masas han generado reacciones que algunos autores (Urbain, 2011, citado Lhérété, 2012b, párr. 11) califican como una nueva contracultura turística, una actitud frente al fenómeno del viaje que pretende contraponerse a la sociedad de consumo y a la cultura de la velocidad. 
En cuanto al relato de viajes, si por las características de nuestra muestra nuestros datos no son generalizables y se limitan a representar el conjunto de relatos escogidos, sí ilustran algunas características presentes en un número cada vez mayor de relatos de viajes contemporáneos. Relatos que transcienden su naturaleza de género literario $\mathrm{y}$, especialmente, muestran su capacidad para transmediatizarse.

Esto hace del relato de viajes un interesante objeto de estudio de las narrativas transmedia no ficcionales. Si el relato de viajes fue en sus inicios oral, luego escrito, -pasando a formar parte de géneros y formas como la literatura, el ensayo, la poesía o el periodismo-, para posteriormente desarrollarse mediante el lenguaje audiovisual y los medios digitales, hoy exhibe su capacidad para expandirse y desarrollar todas sus potencialidades narrativas.

¿Podríamos realmente hablar del nacimiento de una nueva forma narrativa dentro del gran género de la narrativa de viajes, o es únicamente una transformación? Esta pregunta presupone una hipótesis demasiado ambiciosa para defender desde las limitaciones de este trabajo, pero es una cuestión digna de ser estudiada.

\section{Notas}

[1] Puede traducirse al español como El Gran Campamento.

[2] En el marco de una encuesta (Baltar, 2013) realizada durante la edición del Grand Bivouac de 2012, el público citó nombres de algunos de sus autores-viajeros preferidos: Sylvain Tesson, Yann Arthus Bertrand, Jean Louis Étienne, Marianne Chaud, Antoine de Maximy, Daniel Herrero, Nans \& Mout o Caroline Riegel.

\section{Referencias}

Alburquerque, L. (2011). El 'relato de viajes': hitos y formas en la evolución del género. Revista de Literatura, vol. 73 (145), 15-34.

Association pour Le Grand Bivouac (2015). Le projet éditorial. Disponible en: www. grandbivouac.com [recuperado el 22-07-2015].

Bailly, F. (2010). Sur la route du soleil levant. Disponible en : http://florianbailly. com [recuperado el 22-12-2015]. 


\section{MONOGRÁFICO}

Baltar, A. (2013). Le récit de voyage contemporain. Une lecture sociologique. (Tesis de maestría no publicada). Université de Savoie, Departamento de Sociología, Chambéry, Francia.

Béliveau, J. (2015). Marche autour du monde pour la paix et les enfants. Disponible en: http://wwwalk.org [recuperado el 26-12-2015].

Belsunces, A. (2011). Producción, consumo y prácticas culturales en torno a los nuevos media en la cultura de la convergencia: el caso de Fringe como narración transmedia y lúdica. Barcelona: Editorial UOC.

Clocheret, C. y Picard, F (2015). Indochine, sur la Piste rouge. Disponible en: http://www.fr-fr.facebook.com/IndochineSurLaPisteRouge [recuperado el 2212-2015].

Costa, C. y Piñeiro, T. (2012). Nuevas narrativas audiovisuales: multiplataforma, crossmedia y transmedia. El caso de Águila Roja (RTVE), Icono 14, Vol. 10 (2), 102-125. doi: 10.7195/ri14.v10i2.156

Cottereau, A. (2013). Paysan vagabond. Disponible en: https://paysanvagabond. wordpress.com [recuperado el 22-12-2015].

Couture, F. (1999). Enseigner le récit de voyage : le monde dans une classe [versión electrónica]. Revue Québec Français, 112, 66-68.

Dahan, C. y Mingasson, E. (2006). Un an sur la route du lait. Disponible en: http:// www.unansurlaroutedulait.org [recuperado el 22-12-2015].

Étienne y Marion (2015). Notre voyage à vélo en Eurasie. Disponible en: http:// etirion-a-velo.blogspot.com.es/ [recuperado el 22-12-2015].

Fernández, C. (2014). Prácticas transmedia en la era del prosumidor: Hacia una definición del Contenido Generado por el Usuario (CGU). Cuadernos de Información y Comunicación, 19, 53-67. doi: 10.5209/rev_CIYC.2014.v19.43903 Gans, N. (2015). Le Degré 6 du voyageur. Disponible en: http://www.facebook. com/ledegre6duvoyageur/ [recuperado el 26-12-2015].

García, J. y Heredero, 0. (2015). Propuesta de un modelo genérico de análisis de la estructura de las narrativas transmedia, Icono 14, Vol. 13, (2), 260-285. doi: http://dx.doi.org/10.7195/ri14.v13i2.745

Guérin, A. (2015). Lithosphère. Disponible en: http://www.arnaudguerin.com [recuperado el 22-12-2015].

Guerrero, M. (enero-junio de 2014). Webs televisivas y sus usuarios: un lugar para la narrativa transmedia. Los casos de "Águila Roja" y "Juego de Tronos" en 
España, Nueva época, (21), 239-267.

Higgins, 0. y Carrier, M. (2015). Asiemut. Disponible en: http://www.asiemut.com [recuperado el 26-12-2015].

Houlbert, T. y Temps, G. (2014) On plie bagage. Disponible en: http://www. onpliebagage.com/le-blog/ [recuperado el 22-12-2015].

Jenkins, H. (2003). Transmedia Storytelling. Moving characters from books to films to video games can make them stronger and more compelling. Technology Review, 15 de enero. Disponible en: www.technologyreview.com/news/401760/ transmedia-storytelling/ [recuperado el 21-12-2015].

Jenkins, H. (2008). Convergence culture. La cultura de la convergencia de los medios de comunicación. Barcelona: Paidós.

Lepre, L. y Lepre, V. (s.f.). 8 ans à vélo. Disponible en: http://www.veraluc.com [recuperado el 22-12-2015].

Lhérété, H. (2012). L'imaginaire du voyage [versión electrónica]. Magazine Sciences Humaines (240), párr. 3. Disponible en: http://www.scienceshumaines.com/limaginaire-du-voyage_fr_29141.html [recuperado el 23-08-2015].

Lhérété, H. (2012b). Le sens de la marche [versión electrónica]. Magazine Sciences Humaines, (240), párr.11. Disponible en : http://www.scienceshumaines.com/ le-sens-de-la-marche_fr_29154.html [recuperado el 23-08-2015].

MacCannell, D. (1992). Empty Meeting Grounds: The Tourist Papers. Nueva York: Routledge.

Medina, F. y Arango, C. (2014). Comunicación, turismo y ciudad. Medellín: Editorial Universidad Pontificia Bolivariana.

Nils, L. y Clavet, C. (2015). Pianotrip. Disponible en: http://www.pianotrip.com/ [recuperado el 22-12-2015].

Palenzuela, L. y Mercat, M. (2015). Cin'énergie. Disponible en: http://cinenergie. blogspot.com/ [recuperado el 22-12-2015].

Quiquet, F. (22 de julio de 2014). Tour de France des festivals de voyage, d'aventure et de découverte. Un monde de aventures. Disponible en: http://www. unmondedaventures.fr/tour-france-festivals-voyage-daventure-decouverte/ [recuperado el 26-08-2015].

Scolari, C. (2009). Transmedia Storytelling: Implicit Consumers, Narrative Worlds, and Branding in Contemporary Media Production. International Journal of Communication (3), 586-606. 


\section{MONOGRÁFICO}

Scolari, C.A. (3 de abril de 2010). Identikit de las narrativas transmediáticas (según Jeff Gómez), [Mensaje en un blog]. Disponible en: http://hipermediaciones. com/2010/04/03/identikit-de-las-narrativas-transmediaticas-segun-jeffgomez/ [recuperado el 23-08-2015].

Scolari, C.A. (2013). Narrativas transmedia. Cuando todos los medios cuentan. Barcelona: Planeta.

Scolari, C.A. (2014). Narrativas transmedia: nuevas formas de comunicar en la era digital. En Celaya, J. (ed.), Anuario AC/E de Cultura Digital. Focus 2014: uso de las nuevas tecnologías en las artes escénicas. Madrid: Acción Cultural Española.

Riegel, C. (2012). Diary—Baïkal-Bangkok. Disponible en: https://baikal-bangkok. org/ [recuperado el 22-12-2015].

Romero, L. (2005). La reescritura en los libros de viaje: las Cartas de Rusia de Juan Valera. En Romero L. y Almarcegui P. (coord.). Los libros de viaje: realidad vivida y género literario. Madrid: Akal.

Urbain, J. (2011). L'Envie du monde. París : Editions Bréal. 